\title{
Medical advertising and trust in late Georgian England
}

\author{
HANNAH BARKER* \\ School of Arts, Histories and Cultures, University of Manchester, Oxford Road, \\ Manchester, M13 9PL
}

ABSTRACT: This article explores the nature of trust in the fast growing and rapidly changing urban environments of late eighteenth- and early nineteenthcentury England through an examination of medical advertisements published in newspapers in Manchester, Liverpool, Leeds and Sheffield between 1760 and 1820. The ways in which medicines were promoted suggest not just a belief that the market in medicines operated both rationally and fairly, but also a conception that a trustworthy 'public' existed that was not limited to the social elite but was instead constituted of a more socially diverse range of individuals.

In the new and changing urban environments of late eighteenth- and early nineteenth-century England, the sale of medicines and related services appears to have boomed - so much so that the period has recently been described as 'an age of pills and potions'. ${ }^{1}$ Many of the medicines on offer in this period were 'quack' cures, which were likely to have produced little benefit for those who took them in physiological or pharmacological terms, whilst those that might have had a measurable effect on patients were forced to compete with a myriad of other cures. ${ }^{2}$ This article attempts

\footnotetext{
* I am grateful to the Wellcome Trust for funding this project. I am also thankful to Charlotte Wildman and Lucinda Matthews-Jones for their work as research assistants and to the following for comments and suggestions: Michael Brown, Tim Davies, Paul Fouracre, Penelope Gouk, Julian Hoppit, John Pickstone, Pedro Ramos-Pinto, Richard Rodger, Rosemary Sweet and Mick Worboys. I am particularly grateful to Urban History's anonymous readers for their insightful remarks.

1 Quote from S. King, 'Accessing drugs in the eighteenth-century regions', in L.H. Curth (ed.), From Physick to Pharmacology: Five Hundred Years of British Drug Retailing (Aldershot, 2006), 49-78, at 50. See also R. Porter, Health for Sale: Quackery in England, 1660-1850 (Manchester, 1989); R. Porter and D. Porter, 'Rise of the English drugs industry: the role of Thomas Corbyn', Medical History, 33 (1989), 277-95; E.M. Tansey, 'Pills, profits and propriety: the early pharmaceutical industry in Britain', Pharmaceutical Historian (1995), 3-9; F. Doherty, 'The Anodyne necklace: a quack remedy and its promotion', Medical History, 34, 3 (1990), 268-93; P.S. Brown, 'Medicines advertised in eighteenth-century Bath newspapers', Medical History, 20, 2 (1976), 152-68.

2 S.W.F. Holloway, Royal Pharmaceutical Society of Great Britain, 1841-1991: A Political and Social History (London, 1991), 56-7.
} 
to find out how the manufacturers and sellers of successful products, such as Daffy's Elixir, Maredant's Drops, Cordial Balm of Gilead and Hickman's Original Pills managed to attract customers. ${ }^{3}$ In particular, it seeks to understand how the purveyors of such medicines could persuade - at least a proportion of - the public to put their faith in them, specifically by the use of printed advertisements. The marketing of medical products in this period seems to have played a key role in constructing authority and credibility. ${ }^{4}$ Yet despite the existence of some valuable research on medical advertising, ${ }^{5}$ we still know far too little about the relationship between advertising and the consumption of medical goods. It is not apparent why individuals sought out certain treatments rather than others, and what made them believe that they would work. As Sara Pennell has noted, in order to comprehend consuming practices, we need to 'recover the contexts which shaped the motives (conscious and unconscious) informing consuming acts' ${ }^{6}{ }^{6}$ In the case of medicines, we should not overlook the possibility that individual actions could be driven largely by desperation, and as such, do not lend themselves easily to analysis in terms of rational decision-making. However, in such a buoyant market, and with so many products on offer, even the despairing still had to make choices, and unless these were entirely random in nature, they had to be driven by a belief in the efficacy of particular cures. An understanding of the nature of 'trust' on the part of buyers is therefore important, and arguably has implications not just for the history of medicine, but also for our broader understandings of the ways in which consumption operated in this period.

During the late eighteenth and early nineteenth centuries, economic development and population growth transformed towns across England. Urbanization was particularly marked in the industrial and commercial centres of the north, with few places attracting more comments on the nature and pace of change from contemporaries at once excited and horrified by their appearance. ${ }^{7}$ As urban centres expanded, and the

${ }^{3}$ The cordial drink, Daffy's Elixir was particularly long-lived, and was sold for almost 150 years between 1660 and the 1910s: D.B. Haycock and P. Wallis (eds.), Quackery and Commerce in Seventeenth-Century London: The Proprietory Medicine Business of Anthony Daffy, Medical History, supplement no. 25 (London, 2005), 29. On the career of Samuel Solomon, inventor of the Balm of Gilead, see J.A. Picton, Memorials of Liverpool, 2 vols. (Liverpool, 1872-5), vol. II, 253.

4 Though see also Patrick Wallis on the role of apothecaries' shops earlier on in the century: P. Wallis, 'Consumption, retailing, and medicine in early-modern London', English Historical Review, 61, 1 (2008), 26-53.

${ }^{5}$ See e.g. J. Barry, 'Publicity and the public good: presenting medicine in eighteenth-century Bristol', in W.F. Bynum and R. Porter (eds.), Medical Fringe and Medical Orthodoxy 17501850 (London, 1987), 29-39; C. Jones, 'The great chain of buying: medical advertisement, the bourgeois public sphere, and the origins of the French Revolution', American Historical Review, 101, 1 (1996), 13-40; E.L. Furdell, Publishing and Medicine in Early Modern England (New York, 2002).

6 S. Pennell, 'Consumption and consumerism in early modern England', Historical Journal, 42, 2 (1999), 552.

${ }^{7}$ H. Barker, "'Smoke cities": northern industrial towns in late Georgian England', Urban History, 31, 2 (2004), 175-90. 
manufacture and consumption of consumer goods grew apace, ${ }^{8}$ print also proliferated. By the 1760s, most provincial centres had at least one weekly newspaper, with many towns supporting two or three. ${ }^{9}$ To the readers of such publications, medical advertising would have been a familiar sight.

This article examines the appearance of medical advertisements in the newspapers of four northern English towns: Manchester, Liverpool, Sheffield and Leeds, between 1760 and 1820. These towns represent two distinct English regions in this period: the north-west and the West Riding of Yorkshire. Not only were there were strong intra-regional connections between these centres, but each town also exercised a powerful centripetal pull over its surrounding area. As these urban centres grew, their populations witnessed the decline of some traditional forms of word-of-mouth reputation. Despite the existence of strong networks fostered by kin, business and religion within specific communities, growing numbers of these towns' inhabitants would have been strangers to one another. ${ }^{10}$ Establishing trust - an intrinsically tentative and fragile response to ignorance or uncertainty - in societies which were increasingly depersonalized is difficult. ${ }^{11}$ In terms of medical advertising and the consumption of medical goods, where knowledge about those offering goods and services often was not gained first-hand and the possibility of being disappointed seems especially high, understanding trust seems both particularly problematic and important. Roy Porter described what he called the 'speech of quackery' as 'almost entirely one-way: a monologue, harangue, soliloquy, an act of salesmanship instilling confidence, exercising persuasion, disarming resistance' ${ }^{12}$ This depiction of quackery in print also holds true, and certainly means that our understanding of the relationship between seller and buyer is limited. But this article will argue that we can still discover important information from this one-way dialogue, particularly where the issue of trust is concerned, which of course in this context rested entirely with the buyer.

Research by sociologists during the past two decades on the functional properties of trust provide us with useful insights in this area. Giddens, Beck and others have argued that the transition from pre-modern to modern societies brings about changes in the way trust operates: specifically a shift from particularistic or 'thick' forms of trust embedded in highly personal relations such as networks of family and friends to more 'thin', 'social' or 'generalized' forms of trust that involve a greater number of ties and less dense relations, and which eventually become

8 J. Brewer and R. Porter (eds.), Consumption and the World of Goods (London, 1993).

${ }_{9}$ H. Barker, Newspapers, Politics and English Society, 1695-1855 (Harlow, 2000), ch. 2.

10 P. Burke, 'Imagining identity in the early modern city', in C.J. Emden, C. Keen and D. Midgley (eds.), Imagining the City, vol. I: The Art of Urban Living (Bern, 2006), 23-37.

11 D. Gambetta, 'Can we trust trust?', in Gambetta (ed.), Trust: Making and Breaking Cooperative Relations (Oxford, 1988), 213-37; S. Shapin, A Social History of Truth: Civility and Science in Seventeenth-Century England (Chicago and London, 1994), 410.

12 R. Porter, 'The language of quackery in England, 1660-1800', in P. Burke and R. Porter (eds.), The Social History of Language (Cambridge, 1987), 79. 
centred around institutions and abstract capacities thought to reside within them. ${ }^{13}$ For Zucker, 'process-based' trust emerges in modernizing societies before institutional trust and is tied to past or present exchanges. Processbased trust is built incrementally and presupposes a degree of stability and reliability. ${ }^{14}$ This is increasingly difficult to generate as societies become more unstable and heterogeneous, since trusting in those about whom one knows little is inherently risky. ${ }^{15}$ Late eighteenth- and early nineteenth-century urban Britain arguably witnessed the development of more modern forms of thin or social trust and a decrease (though certainly not the disappearance) of more traditional forms of thick trust. Yet in terms of the provision of medicines, this period largely pre-dated the emergence of the sort of institutional controls that would act to regulate them effectively. ${ }^{16}$ In such an environment, an unregulated 'medical marketplace' was allowed free rein. ${ }^{17}$ Indeed, Porter remarked that in those provincial areas where socio-economic transformation was at its most rapid - such as west Yorkshire and the north-west - regulation was at its most limited. ${ }^{18}$ Without the existence of institutionally based trust founded on functions such as certifications or legal constraint, establishing trust in a particular medical product might have been particularly difficult. Yet the apparent dynamism of the market in medicines between 1760 and 1820 suggests that this was not the case, and that even in urban societies in marked states of flux, trust in commodities, and in the individuals who sold and manufactured them, could still be established.

The ability to gain the trust of strangers in early modern cities, simply by virtue of one's dress and demeanour, was something that both

13 U. Beck, Risk Society: Towards a New Modernity (London, 1992); A. Giddens, The Consequences of Modernity (Stanford, 1990). On 'thick' and 'thin' forms of trust see R. Putnam, Bowling Alone: The Collapse and Renewal of American Community (New York, 2000); N. Luhmann, Trust and Power (Chichester, 1979), and his 'Familiarity, confidence, trust: problems and perscriptives', in Gambetta (ed.), Trust; E. Uslaner, The Moral Foundations of Trust (Cambridge, 2002), 94-107.

14 L. Zucker, 'Production of trust: institutional sources of economic structure, 1840-1920', in

S. Bacherach (ed.), Research in Organizational Behavior (Greenwich, CT, 1986), 60.

${ }^{15}$ C. Lane, 'Theories and issues in the study of trust', in C. Lane and R. Bachmann (eds.), Trust Within and Between Organisations: Conceptual and Empirical Applications (Oxford, 1998), $11-12$.

16 Wallis, 'Consumption, retailing, and medicine', 27.

17 This situation was soon challenged later in the nineteenth century: M. Brown, 'Medicine, quackery and the free market: the "war" against Morison's pills and the construction of the medical profession, c. 1830 - c. 1850', in M. Jenner and P. Wallis (eds.), Medicine and the Market in England and its Colonies, c. 1450 - c. 1850 (Basingstoke, 2007), 238-61, at 239; P.S. Brown, 'Social context and medical theory in the demarcation of nineteenth-century boundaries', in Bynum and Porter (eds.), Medical Fringe and Medical Orthodoxy, 216-33; M.W. Weatherall, 'Making medicine scientific: empiricism, rationality and quackery in mid-Victorian Britain', Social History of Medicine, 9 (1996), 175-94; I. Burney, 'Medicine in the age of reform', in A. Burns and J. Innes (eds.), Rethinking the Age of Reform: Britain 1750-1850 (Cambridge, 2003), 163-81.

18 Porter, Health for Sale, 29. See also King, 'Accessing drugs in the eighteenth-century regions'; H. Marland, "The doctor's shop": the rise of the chemist and druggist in nineteenthcentury manufacturing districts', in Curth (ed.), From Physick to Pharmacology, 79-104. 
contemporaries and historians have remarked upon. ${ }^{19}$ This phenomenon is striking because of the apparently flimsy basis on which such trust depended, in contrast to those forms of trust which rested on detailed knowledge. For contemporary observers, it was evidence of the changing nature of human relations in the face of rapid social change. The meanings of trust and credit in urban communities have been explored by historians of the early modern period in relation to personal reputation, but little attention has been paid to the reputation of inanimate objects, such as branded products, or in the context of individuals advertising their services in print. ${ }^{20}$ Medicines were some of the earliest standardized and nationally marked brand-name products sold, ${ }^{21}$ and though there is a large literature on medical advertising, most of this is directed towards exploring the growth of a medical marketplace and assessing how the marketing of goods operated from the point of view of the seller, rather than exploring their relationships with buyers. ${ }^{22}$ For those without strong local ties of reputation such as the majority of those manufacturing medicines, advertisements appear to have offered an important route to securing sales. Though Jonathan Barry has argued that the link between business success and advertising in provincial quackery is not necessarily clear cut $^{23}$ and we must remember that such advertising was often 'free', in the sense that it was reproduced by newspaper printers who doubled up as the sellers of the medicines they publicized ${ }^{24}$ it is still hard to explain the longevity of, and growth in, medical advertising without conceding that it must have enjoyed a degree of success. ${ }^{25}$

Adverts for products such as Clay's Original Ointment, which promised a 'never failing cure for the itch', and Whitehead's Essence of Mustard, which could apparently help those suffering from 'Rheumatisms, Sciatica, Lumbago, Head-ach, Numbness, Palsey, Flatulence and Pains of the

${ }^{19}$ Burke, 'Imagining identity in the early modern city', 31-4.

${ }^{20} \mathrm{~S}$. D'Cruze, 'The middling sort in eighteenth-century Colchester: independence, social relations and the community broker', in J. Barry and C. Brooks (eds.), The Middling Sort of People: Culture, Society and Politics in England, 1550-1800 (Basingstoke, 1994), 181-207; C. Muldrew, The Economy of Obligation: The Culture of Credit and Social Relations in Early Modern England (Basingstoke, 1998); Shapin, Social History of Truth.

${ }^{21}$ J. Styles, 'Product innovation in early modern London', Past and Present, 168 (2000), 12469. On other branded products see R.B. Walker, 'Advertising in London newspapers, 1650-1750', Business History, 15 (1973), 112-30; N. McKendrick, 'George Packwood and the commercialisation of shaving: the art of eighteenth-century advertising, or "The way to get money and be happy"', in N. McKendrick, J. Brewer and J.H. Plumb, The Birth of a Consumer Society (London, 1982), 146-94.

${ }^{22}$ Porter, 'Language of quackery'; Porter, Health for Sale, 44-6; J. Crellin, 'Dr. James's Fever powder', Transactions of the British Society for the History of Pharmacy, 1 (1974), 136-43; and see nn. 1 and 5 above.

23 Barry, 'Publicity and the public good'.

24 P.S. Brown, 'The vendors of medicines advertised in eighteenth-century Bath newspapers', Medical History, 19, 4 (1975), 352-69, at 356-9; P. Isaac, 'Pills and print', in R. Myers and M. Harris (eds.), Medicine, Mortality and the Book Trade (Folkestone, 1998), 25-47.

${ }^{25}$ L.H. Curth, 'Medical advertising in the popular press: almanacs and the growth of proprietary medicines', in Curth (ed.), From Physick to Pharmacology, 46. 
Stomach ${ }^{2},{ }^{26}$ would have been familiar to much of the English population during the late eighteenth and early nineteenth centuries. Advertising as a whole was an important source of newspaper profits and dominated the papers themselves: constituting anything from one quarter to one third of all printed space between 1760 and 1820, and amongst adverts for goods for sale, those for proprietary medicines were particularly prevalent. ${ }^{27}$ Although medical advertising had a significant history before the mideighteenth century, ${ }^{28}$ it was the dramatic expansion of regional newspapers after around 1750 that brought it to a truly national readership, and one with a broad social reach. Although newspaper reading was common in both rural and urban areas, it was at its most inclusive in towns, where higher proportions of the population had access to print than in the countryside..$^{29}$

The discussion of medical advertising that follows is based on an examination of newspapers published in Manchester, Liverpool, Sheffield and Leeds in 1760, 1780 (or 1787/88 in the case of Sheffield), 1800 and $1820 .^{30}$ The survey found a total of 3,278 advertisements. Most adverts were found more than once, and appeared over several weeks in successive editions of the same newspaper, whilst 40 per cent of advertisements appeared in the newspapers of more than one town. Of the total sample, 474 advertisements were identified as unique and non-recurring, promoting the sale of 240 different medical products and services (see Table 1). These figures look to be broadly in line with Brown's survey of Bath newspapers during the eighteenth century, ${ }^{31}$ and suggest that provincial medical advertising assumed roughly equivalent levels in different areas of the country, though there were clearly peaks and troughs in different towns

${ }^{26}$ Billinge's Liverpool Advertiser, 1 May 1820; Leeds Intelligencer, 22 May 1820; The Iris, 2 May 1820; Billinge's Liverpool Advertiser, 25 Aug. 1800; Leeds Mercury, 30 Aug. 1800.

27 J.J. Looney, 'Advertising and society in England, 1720-1820: a statistical analysis of Yorkshire newspaper advertisements' (Princeton University Ph.D. thesis, 1983); Barker, Newspapers, Politics and English Society, 97-8; Brown, 'The vendors of medicines', 352; C.Y. Ferdinand, 'Selling it to the provinces: news and commerce round eighteenth-century Salisbury', in Brewer and Porter (eds.), Consumption and the World of Goods, 393-411; L.F. Cody, " No cure, no money", or the invisible hand of quackery: the language of commerce, credit and cash in eighteenth-century British medical advertisements', Studies in EighteenthCentury Culture, 28 (1999), 103-30, at 105.

28 Styles, 'Product innovation in early modern London'; L.H. Curth, 'The commercialisation of medicine in the popular press: English almanacs 1640-1700', Seventeenth Century, 17, 1 (2002), 48-69; Curth, 'Medical advertising in the popular press'; Furdell, Publishing and Medicine in Early Modern England, ch. 7; K.P. Siena, 'The "foul" disease and privacy: the effects of venereal disease and patient demand on the medical marketplace in early modern London', Bulletin of the History of Medicine, 72, 2 (2001), 199-224; M.E. Fissell, 'The marketplace of print', in Jenner and Wallis (eds.), Medicine and the Market, 108-32.

29 Porter, Health for Sale, 115-27, and Barker, Newspapers, Politics and English Society, ch. 3.

${ }^{30}$ One title was sampled for each town for each year: Manchester Mercury and Williamson's Liverpool Advertiser (continued as Billinge's Liverpool Advertiser), 1760, 1780, 1800, 1820; Leeds Intelligencer, 1760, 1780, 1820; Leeds Mercury, 1800; Public Advertiser (Sheffield), 1760; Sheffield Register, Jun. 1787- Jun. 1788 [in place for 1780 Sheffield papers which are not extant]; The Iris (continued as Sheffield Iris), 1800, 1820.

31 Brown, 'The vendors of medicines', 353. 
Table 1: Counts of medical adverts for each sample year (with \% of annual total)

\begin{tabular}{lcrlc}
\hline \hline & 1760 & 1780 & 1800 & 1820 \\
\hline Leeds & $215(35.1)$ & $181(20.4)$ & $209(21.9)$ & $287(34.8)$ \\
Liverpool & $171(27.9)$ & $268(30.2)$ & $397(41.7)$ & $296(35.9)$ \\
Manchester & $219(35.7)$ & $343(38.7)$ & $169(17.7)$ & $39(4.7)$ \\
Sheffield & $8(1.3)$ & $95(10.7)$ & $178(18.7)$ & $203(24.6)$ \\
TOTALS & $613(100)$ & $887(100)$ & $953(100)$ & $825(100)$ \\
\hline \hline
\end{tabular}

and different papers. Variations were most evident in the papers sampled for Manchester and Sheffield. In the latter case, we can see a steady growth in the number of adverts starting from a very low base. This suggests that the market for medicines in Sheffield was the least developed of the four towns in the late eighteenth century, though its population rapidly developed an appetite for consumer goods such as medicines during the opening decades of the nineteenth century. ${ }^{32}$ The drop in the number of adverts in Manchester papers over time does not reflect a town in decline in this period. Instead we see evidence of the problems of sampling when not all newspapers have survived, and a probable shift on the part of advertisers to different local titles.

Historians of medicine have noted how the language of 'quack' medical advertising in the eighteenth century sought to persuade through a variety of means, including the use of jargon, classical and oriental names, royal and cosmopolitan associations, slick packaging and measures intended to reassure the wary customer, such as manufacturers' boasts of infallibility and the possession of secret methods. ${ }^{33}$ Roy Porter suggested that many medical products also claimed to have a royal patent, which not only implied that the product was worth protecting from counterfeit, but presumably also brought some prestige in the form of a supposed royal endorsement. ${ }^{34}$ Jonathan Barry has described how assertions of efficacy and good intentions in Bristol's medical advertising were supplemented, especially in the early eighteenth century, with more 'traditional testimonies', proving that advertisers had been approved by sources of authority from outside the marketplace, for example by claiming to have aristocratic support or a scientific pedigree. ${ }^{35}$

32 This interpretation is supported by the numbers of chemists and druggists listed over time in Holloway, Royal Pharmaceutical Society, 36.

33 Porter, Health for Sale, 109-10; Barry, 'Publicity and the public good'; Cody, "'No cure, no money"'.

${ }^{34}$ Porter, Health for Sale, 28. Many medicines that claimed a patent did not actually have one: C. MacLeod, Inventing the Industrial Revolution: The English Patent System 1660-1800 (Cambridge, 1988), 86.

35 Barry, 'Publicity and public good', 34 . 
Table 2: Most common marketing methods used as \% of all non-recurring advertisements

\begin{tabular}{lllcc}
\hline \hline & 1760 & 1780 & 1800 & 1820 \\
\hline Name/seal/stamp/bottle & $48(28)$ & $34(37)$ & $25(51)$ & $62(62)$ \\
Accompanying pamphlet & $12(7)$ & $18(20)$ & $16(32)$ & $7(7)$ \\
Claim of longevity & $21(12)$ & $18(20)$ & $7(15)$ & $17(17)$ \\
Royal patent & $33(19)$ & $9(10)$ & $4(8)$ & $3(3)$ \\
Medical endorsement & $28(16)$ & $13(14)$ & $16(32)$ & $18(18)$ \\
\hline \hline
\end{tabular}

These analyses of the marketing methods used in eighteenth-century medical advertisements are important, but they do not tell the whole story. In part, this is because studies often present an impressionistic account of the ways in which adverts sought to persuade. A quantitative analysis of the advertisements located for this study of northern towns reveals a very different picture in which aristocratic, royal, medical or scientific endorsement do not appear as important as other, less commonly discussed methods of encouraging sales. In the 474 non-recurring adverts found for this study, by far the most frequent marketing method was the branding of individual medicines and their identification by means of one or more of the following methods: a uniquely shaped or embossed bottle, a particular form of wax seal and the appearance of a specific name or signature on the bottle or container. Splisbury's Anti-Scorbutic Drops, for example, were advertised as being sold 'in Moulded bottles, with Fluted Corners, and the Words "Frs. Spilsbury, His Antiscorbutic Drops, by the King's Patent", indented on each 5s. bottle'. ${ }^{36}$ An advert for Betton's British Oil claimed that 'No British Oil is genuine, but that which has Dicey and Co. No. 10 Bow Church-yard, printed on the stamp, and signed in the margin of each bill of directions. ${ }^{37}$ As Table 2 shows, one or a combination of branding techniques was used in 25-62 per cent of advertisements over the sample years.

As John Styles has recently demonstrated, the late eighteenth and early nineteenth centuries witnessed a rise in branded products in general, and medicines in particular. According to Styles, 'Branding medicines was a means of establishing a distinct product identity which held out to the consumer a (highly questionable) guarantee of consistent standards and effectiveness. ${ }^{38}$ As Styles also notes, medicines were not the only products to be branded or authenticated in some way. In a study of the publication of interest calculating manuals in the eighteenth century, Natasha Glaisyer has argued that authors' signatures often appeared in order to convince

\footnotetext{
36 The Iris, 21 Feb. 1800, Manchester Mercury; 7 Oct. 1800, Leeds Mercury, 8 Feb. 1800.

37 Billinge's Liverpool Advertiser, 27 Oct., 17 Nov. 1800.

38 Styles, 'Product innovation in early modern London', 149.
} 
readers that the books and the figures they contained could be trusted and were not forgeries. 'In the world of trade, and the new world of the financial revolution', she states, 'the signature was a mark of trust, a guarantee that paper credit could be relied upon. ${ }^{39}$ The provision of distinctive forms of packaging for medicines - including the use of signatures not only ensured that buyers could differentiate branded medicines from those of their competitors, ${ }^{40}$ but also suggested that they might be worth counterfeiting, and, as such, that they held a particular value.

Strategies such as using specially shaped and embossed bottles, the sale of medicines with an accompanying printed bill or pamphlet and the use of a marked wax seal were commonplace before the late eighteenth century, ${ }^{41}$ though in the advertisement sample under discussion, these methods became more prevalent from 1760 onwards. By contrast, royal patents were claimed by an increasingly small number of advertised goods between 1760 and 1820: with a peak of 33 per cent in 1760, falling to 3 per cent by 1820. Roche's Embrocation, a cure for whooping cough in children, was one of very few adverts found in 1820 that proclaimed a royal patent, which in this case was supposedly granted to secure the inventor, J. Roche, 'his valued composition'. ${ }^{42}$ Various forms of medical endorsement, such as claiming to have been invented by medical men or used by them, were in more gradual decline: from 28 per cent of adverts in 1760 , to 18 per cent in 1820. More constant in their use were the provision of pamphlets (often offered 'gratis' $)^{43}$ to support the claims of particular medicines and the inclusion of a boast that medical cures were proved by long experience.

What do these findings tell us about the ways advertisers sought to promote trust in their products? Most striking is their reliance on branding, and, in particular, on protecting an individual brand by devising unique forms of packaging rather than relying (or pretending to rely) on external regulatory bodies, which in this period would have meant purchasing (or claiming to have purchased) a royal patent. Both producing hard-to-copy packaging and securing, or claiming to secure, patents suggested that the purveyors of medical products had something unique and precious to protect from unscrupulous competitors. Perhaps not surprisingly, warnings were issued in advertisements about the dangers of counterfeit medicines. An advert for Cluer, Dicey and Okell's Dr Bateman's Pectoral Drops in 1760, for example, warned readers against purchasing

${ }^{39}$ N. Glaisyer, 'Calculating credibility: print culture, trust and economic figures in early eighteenth-century England', Economic History Review, 60, 4 (2007), 709.

40 Styles, 'Product innovation in early modern London', 151-8; King, 'Accessing drugs in the eighteenth-century regions', 68.

41 Styles, 'Product innovation in early modern London', 151-8; Doherty, 'The Anodyne necklace', 270; Brown, 'The vendors of medicines', 352; Cody, "'No cure, no money"', 117-19, L.H. Curth, 'Introduction', in Curth (ed.), From Physick to Pharmacology, 6.

42 Billinge's Liverpool Advertiser, 17 Jan. 1830; Leeds Intelligencer, 10 Jan. 1820; Iris, 25 Jan. 1820.

${ }^{43}$ See e.g. the advert for Cordial Balm of Gilead, Iris 14 Feb. 1800. A pamphlet for Cordial Balm of Gilead, dating from 1799 and with an attached guarantee and seal, survives in the Liverpool Record Office: 380 MD 131 Acc 2017. 
a counterfeit preparation of the same name, manufactured by Thomas Jackson. A gentleman of Glasgow, it was asserted, 'suffered very greatly, and was in the utmost danger' as a result of taking Jackson's Drops, whilst in Newcastle, a Captain Douglas Russell 'was grossly injured by taking counterfeit Bateman's Drops'. ${ }^{44}$ Similarly, an advert for Jesuit's Drops, which promised to cure 'Stranguary, gleets, and Weakness of the Kidnies [sic] or Bladder', in the Leeds Intelligencer of 1820 warned that

Purchasers should be careful in having the true and genuine Preparation, as the unsafe and dangerous Counterfeits attempted to be foisted on the public, are so numerous, that the proprietors request every purchaser to ask for JOSEPH WESSEL'S Jesuit's Drops. CAUTION. - The genuine WESSEL'S JESUIT'S DROPS are enclosed in a black stamp, with the following engraved thereon, 'JOSEPH WESSEL, St. Paul's Church yard'. ${ }^{45}$

An increasing reliance on commercial methods of product branding rather than regulatory ones suggests that manufacturers did not necessarily feel the need to show approval from sources of authority outside the marketplace, quite the reverse. Whilst a notable (though declining) proportion of advertisements linked products with medical practitioners, such as Dr Brodum's Nervous Cordial, Dr Steer's Opodeldoc and Hill's Honey - 'invented by the late SIR JOHN HILL M.D.' this remained an important, but less common tactic throughout the period $1760-1820 .{ }^{46}$ Instead, advertisers seem to have relied on a dubious understanding of the workings of capitalism: that the medical marketplace could itself act as a regulator in some way, as medicines that worked, and were known to work, were liable to be copied by others, and that this was itself a proof of their efficacy. As long as the customer could be sure they were buying the genuine version of a product, and not a counterfeit or something that sounded similar (hence typical exhortations to 'Be careful to ask for Pike's ointment' or 'Be careful to inquire for "Dr. Freeman's ointment"') ${ }^{47}$ then they could be assured that they were obtaining something of worth. The production of pamphlets by manufacturers (which were, in effect, a form of extended advert) and the general claims made that a product's utility was proven by long experience such as that of the manufacturer of the Oriental Vegetable Cordial who claimed that his product's efficacy was proven by 'the unerring test of ample experience over seventy years ${ }^{\prime 48}$ - were again dependent solely on the actions of the manufacturer and presumptions about the mechanisms of the market: the latter tactic relying at least in part on the logic that

44 William's Liverpool Advertiser, 21 Mar. 1760; Manchester Mercury, 11 Mar. 1760; Leeds Intelligencer, 17 Mar. 1760.

45 Leeds Intelligencer, 10 Jan. 1820 and subsequent weeks.

${ }^{46}$ Leeds Mercury, 13 Dec. 1800; Billinge's Liverpool Advertiser, 3 Jan. 1820; Leeds Intelligencer, 17 Jan. 1820; Iris, 4 Jan. 1820; Manchester Mercury, 4 Jul. 1820; Leeds Intelligencer, 9 May 1780.

47 Billinge's Liverpool Advertiser, 10 Nov. 1800, 22 May 1820.

48 Sheffield Register, 28 Jul. 1787. 
only medicines that worked would continue to be produced, just as only medicines that worked would be counterfeited.

Trusting in the benevolence of a market which was presumed to operate both rationally and fairly was probably naive, but was not uncommon in the eighteenth century. ${ }^{49}$ However, it would be misleading to suggest that sources of authority outside the marketplace carried no weight. It has already been shown that claims of medical endorsement were made in 18-28 per cent of the advert sample over time. The role played by assertions of medical or scientific backing is not unimportant, and suggests that individual expertise was accorded significant weight when trying to promote trust in a product. This gives some support to Steven Shapin's model of early modern scientific truth, in which the gentleman scientist was assumed to be intrinsically trustworthy. ${ }^{50}$ However, as we have seen, links between scientists, medical men and particular medicines were not as important in the sample as a whole as branding, nor do they appear to have been as influential as another form of 'independent' authority - the testimonial - to which we shall now turn.

Testimonials in the sampled newspaper advertisements usually took the form of a letter or a deposition. Letters were generally addressed to a manufacturer and both forms of testimonial purported to be written by disinterested individuals who had witnessed first-hand the utility of a particular product. Letters were common in eighteenth- and earlynineteenth century newspapers, particularly concerning politics, but were usually pseudonymous. By contrast, most testimonials for medicines were signed - usually with a name, and only occasionally with a clear pseudonym such as 'a lady'. In the majority of cases testimonials indicated where the witness lived and around half of all testimonials described their authors in terms of occupation or social status. The inclusion of testimonials in medical adverts published in the four towns was noted in 171, or 36 per cent, of the 474 non-recurring adverts in the sample, and peaked during the last two decades of the eighteenth century (see Table 3). ${ }^{51}$ These 171 adverts included 260 testimonial accounts. In just under half of all cases ( 45 per cent), the nature of the relationship between

${ }^{49}$ On commerce and its reputation see, e.g., N. Glaisyer, The Culture of Commerce in England 1660-1720 (Woodbridge, 2006); J. Hoppit, 'Financial crises in eighteenth-century England', Economic History Review, 39, 1 (1986), 39-58.

50 Shapin, Social History of Truth, chs. 2-3. See also P. Dear, Discipline and Experience: The Mathematical Way in the Scientific Revolution (Chicago, 1995); M. Poovey, A History of the Modern Fact: Problems in Knowledge in the Sciences of Wealth and Society (Chicago, 1998). Cf. D.E. Harkness, The Jewel House: Elizabethan London and the Scientific Revolution (New Haven, 2007), which argues that early modern science was created by the members of urban communities who were not necessarily elite, whilst M. Knight's Representation and Misrepresentation in Later Stuart Britain: Partisanship and Political Culture (Oxford, 2005) suggests that political truths and untruths in later Stuart Britain were also produced by members of a relatively broad-based public.

51 A similar study has been undertaken by T. Davies as part of his on-going doctoral research at the University of Leicester, 'The promotion and pursuit of health in the nineteenthcentury town, $1780-1880$ '. I am grateful to him for a copy of a draft of chapter 5, 'The 
Table 3: Appearance of testimonials in advertisements as \% of all non-recurring adverts

\begin{tabular}{rr}
\hline \hline 1760 & $6(11)$ \\
1780 & $24(41)$ \\
1800 & $58(99)$ \\
1820 & $12(20)$ \\
\hline
\end{tabular}

patient and witness was not specified. In 31 per cent of the remaining testimonials the witness supposedly described their own cure, whilst 13 per cent of testimonial accounts were written by family members (fathers, husbands and mothers), 2 per cent were provided by clergymen writing about their parishioners and a further 2 per cent were provided by the employers or landlords of the recovered patient. Only 5 per cent of testimonials were written by those who had supplied the medicines to the patient in a professional capacity, as medicine sellers and doctors. Although the number of advertisements including testimonials in the sample changed significantly over time, the ratios between these different types of relationships altered little between 1760 and 1820 .

A typical testimonial included a case history which outlined symptoms suffered and length of illness, a description of other cures tried and failed (in the form of other medicines and treatment by medical practitioners) and concluded with the description of how a final recourse to the advertised medicine led to the resumption of good health. This model was well established by 1760, when this survey begins. In the Manchester Mercury of September 1760, for example, it was announced that:

\section{SARAH MAKIN}

Wife of Thomas Makin in Hanging-ditch, Manchester having been afflicted with an Obstruction in the Stomach and bowels, rattling in the Throat, Palpitations of the heart, nervous Twitchings and violent Asthma, attended with the utmost Difficulty in Breathing for 15 years, and hath scarcely rested in Bed one night for 12 years past without the greatest Danger of Suffocation, do declare and am willing at any Time, if required, to attest the same upon Oath, that having tried almost every medicine that I could hear of, without finding the least Relief, being persuaded to take only a few doses of Dr Radcliffe's Specifick Tincture, of which I have not yet taken One Half Crown bottle, the Effect of these Drops have been so great, that they have eradicated all the above mentioned complaints, and wrought such a miraculous Cure, that I am now able to perform my Business as before. ${ }^{52}$

language of advertisements for health products', which samples newspapers in Leicester, Liverpool and Reading during the 1780s, 1830s and 1880s.

52 Manchester Mercury, 23 and 30 Sep. 1760. 
Although testimonials became more common and frequent in the adverts sampled towards the close of the eighteenth century, the rhetoric and language used varied surprisingly little over time. So, for example, an advert testimonial for Cephalic Snuff which appeared in the Leeds Intelligencer in 1820 followed the same lines as Sarah Makin's deposition sixty years earlier. It included 'the following unsolicited testimony' which it was claimed was 'a recent confirmation of its efficacy':

Two years ago last winter, I was seized by a violent cold and chill, accompanied with much pain in my head. I was attended by an eminent medical gentleman a considerable time; my head was blistered for more than a month; I took various medicines but without effect. At length I was recommended to try the CEPHALIC SNUFF; I purchased a canister, and much to my surprise as well as comfort, I found considerable relief from its use. I have continued to take it very frequently to this day; and I can truly say that I have experienced more benefits from its use than all the medicines recommended during my illness.

\section{ISAAC ADAMS}

Handley, Dorset, May 16, $1820^{53}$

As the references to oath-making and testimony in these two examples suggest, such testimonials appear to have been modelled not just on the letter form, but also on established legal models. The use of both the language and rhetoric of court witness statements and affidavits lent the advert testimonials another layer of credibility, which, like the letter form, had long been associated with the provision of authoritative accounts and the first-hand reporting of events. ${ }^{54}$ But testimonials, and medical advertisements in general, also appear to have drawn inspiration from another established printed literary form - the reporting of miraculous cures - which, as Jane Shaw has demonstrated, was commonplace in the seventeenth and early eighteenth centuries, ${ }^{55}$ and which continued amongst Roman Catholics and certain Protestant sects, such as the Quakers, much later than this. There was a remarkable consistency in terms of the stories told and the language used by the testimonial witnesses in the sample - whether they described their own cures or those of others and whether they were male or female. Cures were termed 'remarkable', 'surprising', 'extraordinary' and 'wonderful' to underline the wondrous and unique nature of the product involved. Here advertisers clearly drew not just in terms of form on the traditional first-hand reporting of miraculous cures, but also on the religious language of miracles, so that a mode of writing that was originally used to corroborate religious experience was now being used for a secular purpose.

${ }^{53}$ Leeds Intelligencer, 19 Jun. 1820.

54 B.J. Shapiro, A Culture of Fact: England, 1550-1720 (Ithaca, 2000).

55 J. Shaw, Miracles in Enlightenment England (New Haven, 2006). 
Testimonials in letter-form commonly claimed to have been written in gratitude for the cure that had been received, and for the public good, thus further emphasizing their impartiality. The testimonial writer for a Mrs Saunders, who had suffered from 'the most excruciating pains in her head' from her youth which were finally cured by taking a 'Vegetable Cordial', asserted that 'You have Mrs Saunder's consent to make what use you please of this, but it is her desire it may be made public for the good of others who may labour under the like complaint.' John Crandon, who had witnessed Mrs Saunders' cure, described her as residing in 'Huntspile, about seven miles' from his own address in Bridgewater. ${ }^{56}$ The tendency to include both the name and the location of testimonial writers increased significantly after 1780, and in the 1800 and 1820 samples, 92 per cent of advertisements containing testimonials gave the author's location, compared to less than half of advertisements in earlier years. In common with Sarah Makin's deposition, this offered readers the chance to confirm the stories they told either in person or by post, hence reassuring the reader that a more direct affirmation of a product was possible (even if it was never followed up). ${ }^{57}$ Using other sources, it is possible to trace some of the individuals who appeared in medical testimonials. John Barlow and David Torr of Oldham Street in Manchester, for example, who signed an affidavit which appeared in both the Manchester Mercury and the Leeds Mercury in 1800 concerning the cure of John Harron using Dr Paterson's Vegetable Drops can both be found in Banck's Manchester and Salford Directory for 1800, where they appear as 'John Barlow, grocer and tobacconist' and 'David Torr, Brush-maker' at 70 and 71 Oldham Street respectively. ${ }^{58}$ Richard Collins, 'Minature Painter to His Majesty, 24 Pall Mall' appeared in Billinge's Liverpool Advertiser, also in 1800, claiming that a Botanic Syrup and Nervous Cordial may have saved his sight. ${ }^{59}$ In common with Barlow and Torr, Collins evidently was not a figment of the advertiser's imagination, and was indeed a royal portrait painter during the late eighteenth century, living for at least some of this time on Pall Mall. ${ }^{60}$

Reliance on the testimony of others in order to establish knowledge is, as Shapin points out, a cultural practice of long-standing. ${ }^{61}$ But the testimonials used in the medical adverts which appeared in Manchester, Liverpool, Sheffield and Leeds did not conform to Shapin's model in which the 'gentleman' constitutes the most reliable type of truth-teller. ${ }^{62}$ Rather, they depict a more complicated vision than we might expect concerning

\footnotetext{
56 Billinge's Liverpool Advertiser, 4 Aug. 1800.

57 See e.g. Manchester Mercury, 4 Nov. 1800; Iris, 4 Jan. 1820.

58 Manchester Mercury, 9 Sep. 1800, and Leeds Mercury, 13 Dec. 1800; Banck's Manchester and Salford Directory (Manchester, 1800).

59 Billinge's Liverpool Advertiser, 10 and 24 Nov. 1800.

60 V. Remington, 'Collins, Richard (1755-1831)', Oxford Dictionary of National Biography (Oxford, 2004) (www.oxforddnb.com/view/article/5949, accessed 2 Feb. 2009).

61 Shapin, Social History of Truth.

62 Ibid., chs. 2-3.
} 
Table 4: Social status/occupations of witnesses and patients in testimonials in advertisements as $\%$ of all adverts with testimonials

\begin{tabular}{llc}
\hline \hline & Witnesses & Patients \\
\hline Unspecified & 51 & 73 \\
Elite & 20 & 10 \\
Trade & 16 & 8 \\
Professionals & 9 & 4 \\
Lower class & 1.5 & 3 \\
\hline \hline
\end{tabular}

the status and location of both patients and witnesses. The occupation and social status of the 260 witnesses cited in the adverts sampled varied widely, and spanned cheesemongers, weavers and innkeepers as well as clergymen, surgeons and aristocrats. Half of all testimonials located (51 per cent) did not indicate anything about the social status of the witness, though a name and location was almost always given. Of those testimonials that did indicate something about the standing of witnesses, 20 per cent were members of the elite (gentry, aristocracy, JPs, clergymen), 16 per cent were in trade (for example, booksellers, printers, bakers, butchers, shoemakers), 9 per cent came from the professional classes (such as army officers, surgeons, the wives of attorneys) and 1.5 per cent were sailors. Only 3 per cent of testimonial witnesses were in medical trades and professions (an apothecary, a druggist, a chemist, a doctor and four surgeons: organized in the analysis as members of both the professional and trading classes).

As Table 4 shows, in terms of the occupation and social status of the 260 patients described, once again the largest group had neither occupation nor social status specified. However, in the case of patients this trend was more marked than for witnesses at 73 per cent, which suggests that the social status of witnesses could be seen as more significant than that of patients. Of the remainder, 10 per cent were members of the elite (gentlemen, ladies and an archdeacon), 8 per cent were in trade (bakers, grocers, booksellers and their dependent relations, a tailor and a plumber), 4 per cent were professionals (army officers, a clergyman and a schoolmaster), and 3 per cent were lower class (apprentice, sailors, servant, waiter and a domestic). There were no obvious trends over time in terms of the social status of either witnesses or patients and the highest numbers in most categories peaked in 1800, in line with the peak of adverts with testimonials (and all medical adverts) in that year.

Roy Porter noted the widespread use of testimonials in his studies of medical advertising, but stated that 'For obvious reasons, those whose miracle recoveries were dramatized were members of the respectable 
classes - the occasional gentleman or titled lady, clergyman, Justices of the Peace, church-wardens, merchants, provincial mayors, and so forth. ${ }^{63}$ Several advertisements were found in this sample which did seem to lay particular emphasis on the elite status of a witness or patient. This was especially notable in adverts placed by the London-based manufacturer, Mr Ching. One advert for his 'Patent Worm Lozenges' which appeared in the Leedes (sic) Intelligencer of 25 March 1760, boasted of 'the respectability of the testimonies with which Mr CHING has been honoured from Noblemen and ladies of the highest rank'. Another advert for his worm lozenges from 1800 included a testimonial which purported to come 'From a noble earl' who had used them to treat his servant who had been 'unable to get up from her bed for above nine weeks' due to 'an Obstruction in the first passages and bowels' ${ }^{64}$ In another, a letter signed by the bishop of Carlisle describes the effect of the lozenges on his son. ${ }^{65}$

Yet in terms of the sample as a whole, neither patients nor witnesses appear to have been overwhelmingly elite. Porter also suggested that quack advertising was increasingly aimed specifically at elite customers, thus 'Empirics selected their brand-names to chime with the fashionable, elitist, progressive aspirations of Enlightenment high society, evoking the reputations of top scientists, the cosmopolitanism of exotic wisdom, the philanthropic associations of ecumenical religion, the benevolence of the Great. ${ }^{\prime 66}$ But it seems likely that the wealthy ill would consult with physicians, or at least apothecaries, rather than choosing to selfmedicate. The advertised price of medicines in this survey of northern English newspapers varied between products and over time from just over a shilling to more than a guinea, though the majority of medicines were advertised for between one and three shillings. ${ }^{67}$ Such sums were not negligible, though at the cheaper end they were increasingly within the reach of artisans and tradesmen. ${ }^{68}$ Indeed, though he stressed their links with members of the elite, Porter also allowed that the buyers of quack

63 Porter, Health for Sale, 52-3. See also Brown, 'The vendors of medicines', 353-4; Cody, '“No cure, no money"', 109.

64 Manchester Mercury, 14 Jan. 1800.

65 Iris, 10 Jan. 1800.

${ }^{66}$ Porter, Health for Sale, 47.

${ }^{67}$ Not all advertisements in the sample listed a price, though many did, particularly where they solicited orders by post. The most expensive medicine found was Spilsbury's Antiscorbutic Drops, which was advertised for 1 guinea 2s in 1800, although a smaller bottle could be purchased for 5s: Manchester Mercury, 14 Oct. 1800. At the other end of the scale, and in the same year, small bottles of Daffy's Elixir were advertised for 1s $4 \mathrm{~d}$, Dr Radcliffe's purging elixir for $1 \mathrm{~s} 1 \frac{1}{2} \mathrm{~d}$, Hooper's female pills for $1 \mathrm{~s} 1 \frac{1}{4} \mathrm{~d}$ and Squire's grand elixir for 1s 8d: Billinge's Liverpool Advertiser, 27 Oct. 1800.

681 shilling represented perhaps $20 \%$ of a craftsman's weekly wage in 1760 , but only around 4\% by 1815: J. Rule, Albion's People: English Society, 1714-1815 (Harlow, 1992), 168, 182-4. According to Joseph Massie's estimates in 1759, 1 shilling would constitute around $10 \%$ of most tradesmen's weekly income: P. Langford, A Polite and Commercial People: England, 1727-1783 (Oxford, 1989), 64. Though the price of medicines did rise between 1760 and 1820 , this seems to have been at a much lower rate than rises in wages. 
medicines may well have been less elevated and come from amongst the broad middle ranks of society. ${ }^{69}$

Lisa Cody suggests early eighteenth-century quack medicines 'appealed to their readers as if they were gentry' even though they might not have been: 'The public sphere of print culture', she argues, 'relied on a fiction where participants acted as if they were elite, and their problems genteel, whether they actually were or not. ${ }^{, 70}$ Yet by the later eighteenth and early nineteenth centuries, it is not at all clear that medical advertising pretended to represent genteel or polite society and we have seen how the numbers of elite witnesses who appeared in testimonials were almost equalled by those in trade. Moreover, by far the largest proportion of both the witness and patient samples were comprised of individuals whose status was unspecified. In these cases it seems that what really mattered was not social standing but the testimonial writer's ability to appear as an impartial and trustworthy witness to events. This impartiality may have been given greater credence by a full description of the individual concerned - hence the fact that a greater proportion of testimonial witnesses than patients were described in terms of occupation or status - but it was arguably the fullness of the description, rather than the standing of the individual, which counted, which is why the location of a cure was almost always provided, especially in the later years sampled, even if the occupation or social standing of the witness or patient was not.

The testimonial, then, can be seen as a far more democratic device than Porter allowed. The form and use of testimonials in medical advertising suggests that truth-telling was not recognized as the preserve of the social elite and more specifically, the figure of the gentleman. Thus 'Gardener's Celebrated Chemical Oil, for the cure of corns in the feet' was advertised in Billinge's Liverpool Advertiser during 1800 with supporting testimonials from various individuals in and around Paisley where the oil was produced, including John Harper, a carrier, John Jamieson and Alexander Sloan, both weavers, an unnamed 'gentleman of respectability', and John Ewing, James Jephson and David Cameron, whose occupations were not given. ${ }^{71}$ Similarly, Dr Brodum's Botanical Syrup and Nervous Cordial was advertised with testimonials from a Lady McLean, an Irish aristocrat who had taken the remedy at Bath, and Mrs Jewel, a linen draper from Chatham in Kent. ${ }^{72}$ Rather than display the sort of London bias that one might expect from an elite-dominated sample, testimonials purported to come from all over Britain (with one from Norway and one from on board a ship). Where the location of a cure was given, 13 per cent supposedly emanated from London, 18 per cent were from those northern counties where our sample towns were situated (Lancashire and Yorkshire)

69 Porter, Health for Sale, 52.

70 Cody, "'No cure, no money"', 108.

71 Billinge's Liverpool Advertiser, 12 May 1800.

72 Ibid., 3 Nov. 1800. 
and the rest were spread across the rest of England, Scotland and Wales (69 per cent). The regional diversity of advertisements is also striking given the dominance of London in the manufacture of medicines, ${ }^{73}$ and suggests both the established nature of the national market in this period, and a desire on the part of advertisers to demonstrate that they sold their goods and effected cures on a country-wide basis.

In a study of Victorian advertising, Lori Anne Loeb has described the public testimonial as making readers feel part of a community of consumers whose collective experience engendered confidence in a particular product. ${ }^{74}$ The sorts of testimonials that appeared in medical advertisements in the earlier period under discussion here can be seen in similar terms, by allowing a form of 'remote' face-to-face encounter, which provided the reassurance of receiving evidence that a medicine worked from a real person, even if one did not actually meet them. What is most notable is that the 'real person' in this instance was not a medical practitioner, nor were they necessarily a member of the social elite, but an individual who typically appeared in print with no indication of his or her social standing or of their expertise to comment on medical matters. Indeed, it is implicit in most testimonials that writers had no medical training and were unconnected to the medical trades and professions. Testimonials were supposedly provided by individuals who were willing to publicize their cures and have their names in print, but who - in the main were distinguished only by their 'ordinariness'. In this way, testimonial writers appeared to stand in for those day-to-day contacts who would have provided the type of word-of-mouth reputations upon which most people might have depended previously, aping something of the 'thick' forms of trust that were more prevalent when towns were smaller and their populations less diverse and unconnected.

Cody has suggested that the quack medical products advertised in the press appealed to individuals who did not want the embarrassment of a face-to-face encounter (in the case of her argument, specifically one with a medical practitioner).$^{75}$ Yet whilst many medicines were advertised as being available by post, 83 per cent of the adverts examined also included lists of locally based sellers who were generally members of the local

73 Of the 164 manufacturers identified in the adverts sample, $61 \%$ were London-based, $13 \%$ were from the sample towns, $11 \%$ were of unknown location, $1 \%$ were foreign (Dutch and German) and the remainder (14\%) were located throughout England and Scotland. Porter notes the rise of London as a medical centre in the eighteenth century: 'Laymen, doctors and medical knowledge in the eighteenth century: the evidence of the Gentleman's Magazine', in Porter (ed.), Patients and Practitioners: Lay Perceptions of Medicine in PreIndustrial England (Cambridge, 1985), 285. See also Holloway, Royal Pharmaceutical Society, 37-42. The London manufacturing dominance in the provinces was also evident earlier in the eighteenth century: P.S. Brown, 'Medicines advertised in eighteenth-century Bath newspapers', Medical History, 20, 2 (1976), 152-3.

${ }^{74}$ L.A. Loeb, Consuming Angels: Advertising and Victorian Women (Oxford, 1994), 143-5.

75 Cody, "'No cure, no money"', 110. 
trading community, such as printers and shopkeepers (including chemists and druggists). Their role as designated vendors meant that consumers had direct contact with a manufacturer's agent, if not with the manufacturer themselves, whilst they also offered the possibility of redress for those customers who discovered that a particular cure did not work. With the exception of chemists and druggists, it is unlikely that the army of booksellers, printers and other small traders who sold medicines in provincial towns were trusted for their medical expertise. But it is probable that their standing in their local communities was important, so that we can see trust in a particular product as dependent not just upon the type of marketing techniques discussed above, but also on the reputation of what sociologists of trust, such as Zucker, term 'intermediaries' in the operation of thin trust. ${ }^{76}$ Yet in this context, one might more plausibly see local sellers - who would presumably vouch for the goods they sold and whom many buyers knew - in terms of older forms of personal or thick trust.

Indeed, though adverts have generally been depicted in this article as evidence of thin forms of trust, they explicitly linked the use of particular products to more traditional forms of reputation, and it was a common trope in testimonials that individuals had been recommended a particular medicine by neighbours. Thus in one advertisement we are told that the Devonshire cheese factor, William Elworthy, 'thought of nothing but the grave' such was the hopelessness of his case, until 'providentially hearing of many cures performed in his neighbourhood' by Daffy's Elixir. ${ }^{77}$ Whilst in another, Jonathan Foster from Newcastle-upon-Tyne professed to trying a medicine on his son after 'Observing numerous advertisements of yours in the newspapers, and the many cures your Antiscorbutic Drops performed in this neighbourhood..$^{78}$

Foster's description of his recourse to both newspaper advertising and neighbourhood connections when searching for a cure for his son reminds us again of the changing nature of trust in the fast growing and rapidly changing urban environments of late eighteenth- and early nineteenth-century England. In medical advertisements we see evidence of individuals relying both on those traditional forms of thick trust which centred around family, friends and neighbours, and thinner forms of trust linked to the development of increasingly depersonalized and outward looking urban societies. Yet as we have seen, and contrary to what might be expected, advertisers did not seek to promote their products by claiming elite or learned connections in the main, nor did they invoke the sanction of external regulatory bodies as a rule. More commonly they sought to persuade potential customers to trust their goods by the use of branding and the publication of testimonials. These methods sought to create thin

76 Zucker, 'Production of trust'.

77 Williamson's Liverpool Advertiser, 8 Aug. 1760.

78 Billinge's Liverpool Advertiser, 3 Nov. 1800; Manchester Mercury, 4 Nov. 1800. 
forms of trust by imitating and emulating some of the processes of thick trust. In addition, medicines were promoted in ways which suggest not just a belief that the market operated both rationally and fairly, but also a conception of the 'public' in this period that was not limited to the social elite but was constituted of individuals who could be trusted nevertheless. Medical advertising in the late eighteenth and early nineteenth centuries is traditionally associated with superstition and quackery. This analysis suggests that instead it can be seen - at least in part - as the product of modernity. 